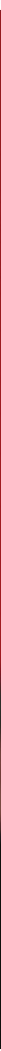

China's many hopeful and determined graduates take their place in a rich and varied research landscape that is transforming the country's fortunes.

\title{
THE RAPID RISE OF A RESEARCH NATION
}

China's economic boom is mirrored by its similarly meteoric rise in high-quality science.

\section{BY YINGYING ZHOU}

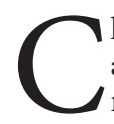

hina has ambitious plans to source as much as $15 \%$ of its energy from renewable sources by 2020 , at the same time its economy is projected to slow. It also aspires to be the next space superpower while facing major health and environment challenges, such as an ageing population and water shortages.

The Chinese government knows that surmounting these challenges while achieving its goals can only be accomplished through science. Indeed, China is pegging its future prosperity on a knowledge-based economy, underpinned by research and innovation. For a country that invented paper, gunpowder and the compass, such lofty ambitions could be realized. This year pharmacologist Tu Youyou became the first Chinese researcher to be awarded a Nobel Prize in Medicine for helping discover a new drug for malaria that has saved millions of lives.

"With a solid base built upon the large quantity of research, China is [about] to take off in world-leading innovations and scientific breakthroughs," says He Fuchu, the founding president of PHOENIX, the Chinese National Center for Protein Sciences. "High-quality research is built upon the accumulation of incremental advances," He says.

The Nature Index shows China is already a high-quality scientific powerhouse. Since the first Nature Index database started in 2012, China's total contribution has risen to become the second largest in the world, surpassed only by the United States.

But, what sets China apart is the rapid growth of its WFC. While China's contribution grew 37\% from 2012 to 2014, the United States saw a $4 \%$ drop over the same period.

\section{AN ECONOMIC IMPERATIVE}

A key driver of China's scientific progress is its burgeoning economy, dazzling the world since embarking in the early 1980s on a transformation from a centrally planned to market-based economy. In the past three decades, China has achieved a consistently impressive annual average GDP growth rate of around 10\%, and has overtaken Japan to become the world's second largest national economy behind the United States.

"The economic success has fuelled the nation's investment in science and technology," says Liu Zhu, a researcher at Harvard University's Kennedy School of Government, who is also currently a fellow in sustainability science at the California Institute of Technology. While China's unfettered growth cannot last forever - economic growth has slowed, with the GDP growth rate falling to $7.4 \%$ last year, its lowest in 25 years - it has been the subject of global awe and fascination.

Figures from the National Bureau of Statistics of China show that during the past decade the nation's total research and development (R\&D) expenditure also blossomed, achieving an average growth rate of more than $20 \%$. In 2014, R\&D expenditure totalled 1,330 billion yuan, equivalent to $2.1 \%$ of the national GDP. China's rapid growth trajectory in R\&D investments is in sharp contrast to the constraints placed on R\&D budgets of the United States, Japan, and most European countries, still recovering from the global economic crisis that began in 2007 .

Recognizing the importance of scientific research in driving technological innovation and economic progress in 2006, the Chinese government unveiled its National 


\section{CHINA BOOMING}

This cross-section of countries in the Nature Index shows how remarkable China's increase in high-quality science output has been in recent years.

\section{CHEMISTRY CHAMPS}

Change in output of the top five leading countries in chemistry.

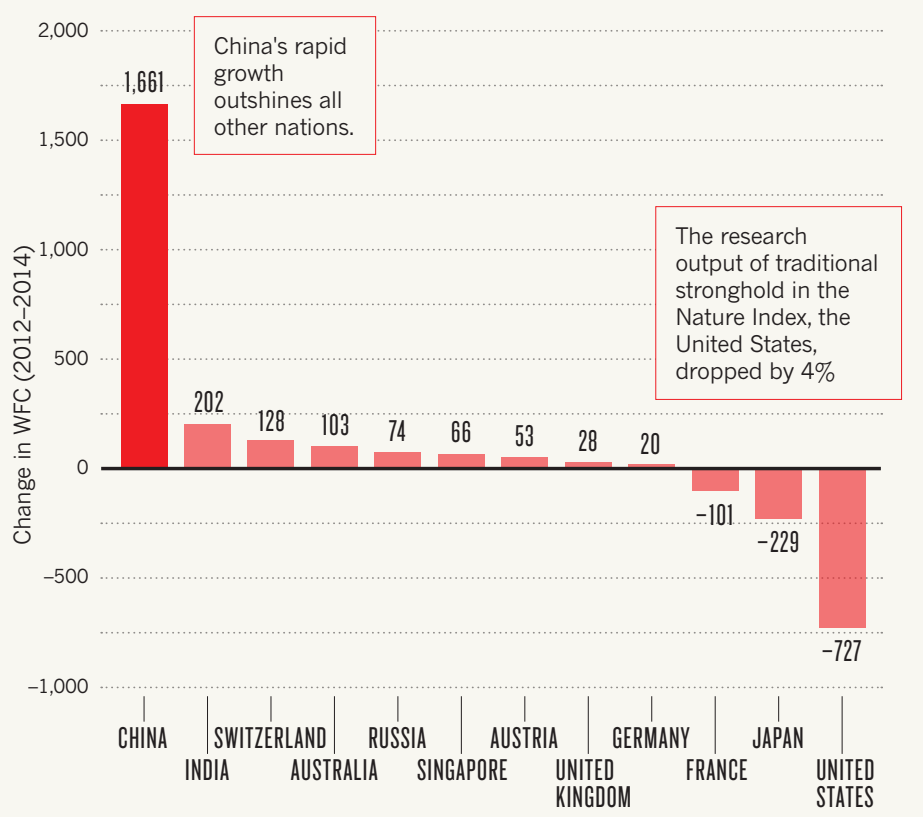

Medium- and Long-Term Plan for the Development of Science and Technology, setting out a path to transform the country into a "science powerhouse" by 2020. The 15-year plan called upon an "indigenous innovation" campaign, putting science and technology development at the centre of the national development strategy. Under the strategy, investment in higher education was emphasized, recognizing that human resources are at the heart of scientific development.

China has made great efforts to expand its higher education system and enlarge its scientific workforce. The number of $\mathrm{PhD}$ graduates in science and engineering has soared in the past decade along with the number of graduates with bachelor degrees. Central and local government efforts to attract Chinese-born

"China has the
chance to be a
research giant
and establish
a long-term
culture of
innovation."
scientists to return from overseas work and study have also paid off. The prominent 1,000 Talent Plan initiated in 2008 by the Central Organization Department of the Chinese Communist Party has hugely exceeded its eponymous goal, having attracted more than 4,180 top-level scientists from abroad by mid-2014. The cumulative number of returned $\mathrm{PhD}$ holders reached 110,000 in 2014.

"The improvement of the research capabilities of Chinese researchers and the returning of foreign-trained Chinese scientists from overseas certainly adds to the momentum of China's scientific growth," says Wang Jun, the former chief executive officer, and now partner, of successful genomics sequencing company BGI. David Reiner, a senior lecturer in science and technology policy from Cambridge University's business school and a keen observer of China, says the return of its large scientific diaspora also fosters a supportive research culture.

With a deep cultural reverence for education, the Chinese hold scientists and their research in high regard. "The government investment and promotion, combined with

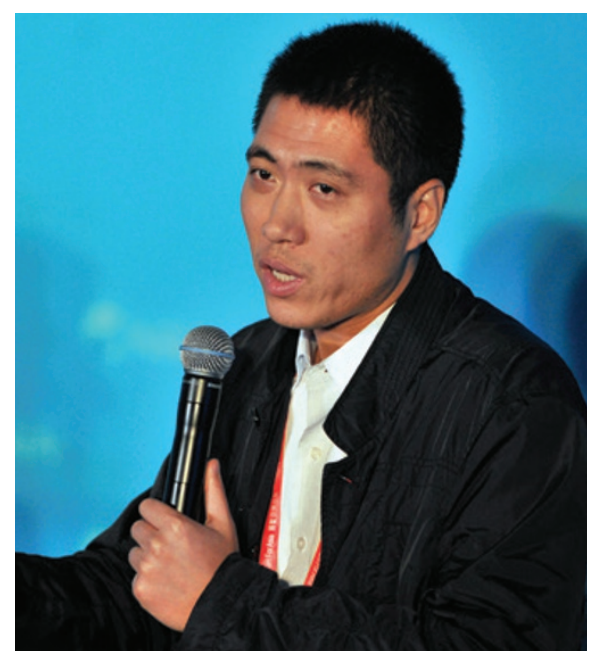

Wang Jun says returning scientists help growth. the determination of Chinese scientists and societal support have fostered a culture of innovation," says Wang. "China now has the opportunity not just to be seen as a global research giant but also to establish a longterm culture of innovation that will undoubtedly lead to myriad scientific discoveries in decades to come."

\section{BOLSTERING QUANTITY WITH QUALITY}

The research assessment system has also played a role in China's rapid growth in output. An increasing focus on evaluation systems that measure quality is shifting emphasis from quantity-driven metrics. Most universities and research institutions now evaluate researchers based on the number of publications in highimpact journals rather than the sheer volume of publications, according to Ren Xiaobing, chairman of Xian Jiaotong University's Frontier Institute of Science and Technology.

But Reiner warns that the increased pressure on researchers to focus solely on publishing their work in academic journals could encourage academic fraud. "The downside of an exclusive focus on quantitative metrics is that they may blind what is really important to research, making it difficult for scientists to explore blue-sky research ideas," he says.

Some major research institutions, such as the Chinese Academy of Sciences (CAS) and prestigious universities, such as Xian Jiaotong University, are beginning to include other evaluations in their researcher assessments. "Other than the criterion of high-impact publications, 


\section{COLLABORATION HOTSPOTS}

This map shows countries that have experienced an increase in their collaboration score with China between 2012 and 2014. Collaboration score $=$ sum of the fractional count (FC) for each of China's bilateral partnerships.

\section{ABSOLUTE COLLABORATION SCORE INCREASE \\ No increase/no data $<5$ \\ 5-9 \\ 10-19 \\ 20-29 \\ 30-79 \\ 80-149 \\ 150-299 \\ - $>900$}

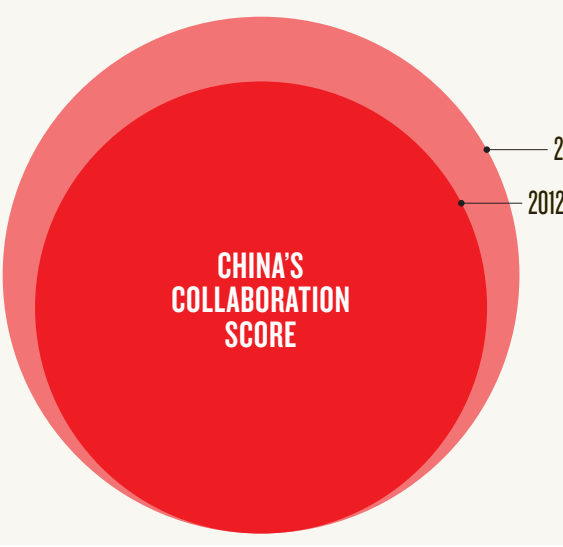

2014:9,713 2012: 7,431

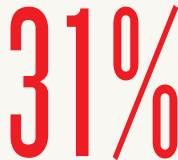

Increase in collaboration score 2012-2014.

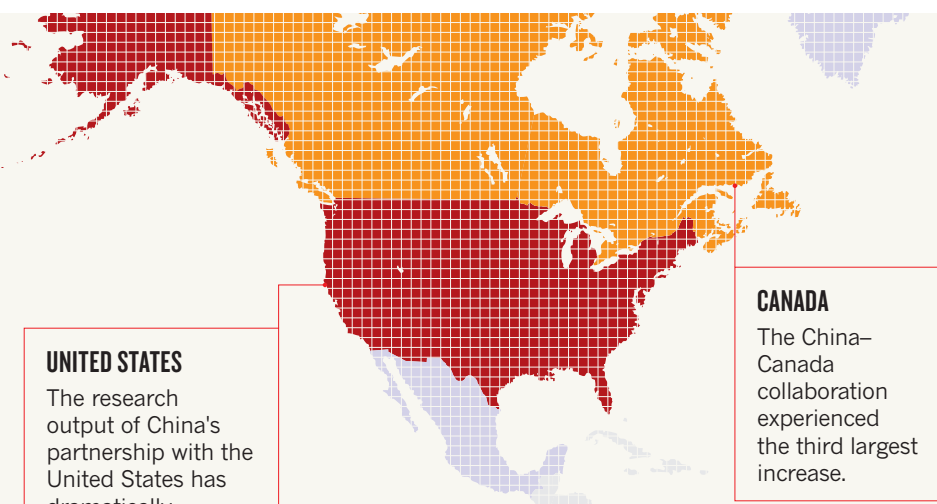

dramatically

increased its

collaboration score

from 3,714 in 2012

to 4,664 in 2014 , a rise of 949 .

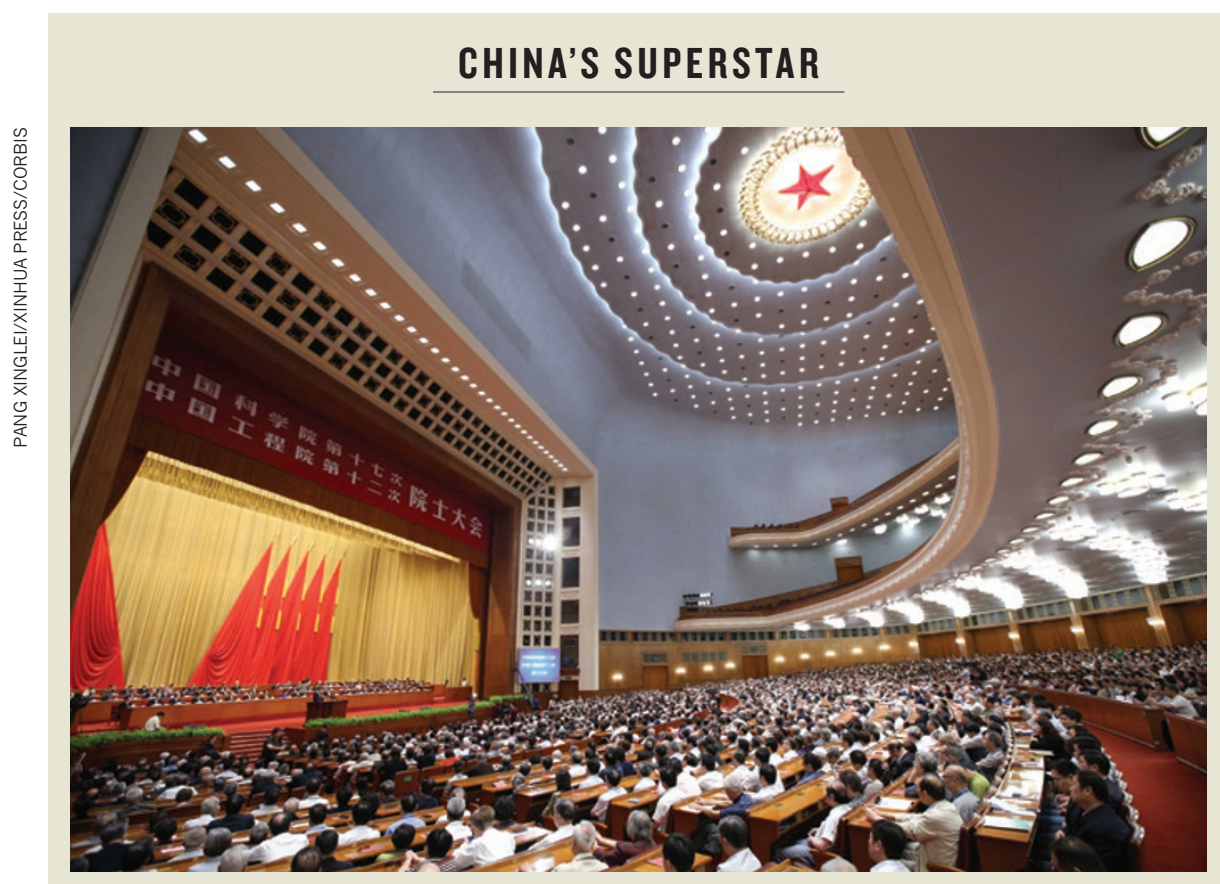

A congress of the Chinese Academy of Sciences, a central plank of the country's research prowess.

The Chinese Academy of Sciences (CAS) is the world's largest institutional contributor to the Nature Index. In 2014 its WFC was 1,308 (its $A C$ was 3,124 ), significantly higher than that of the second-ranked institution, Harvard University, with a WFC of 865. By subject areas, CAS leads not only in chemistry, but also in physical sciences, and earth and environmental sciences, with higher WFCs in these major subject areas than any other research institutions worldwide. CAS employs more than 60,000 people, has 104 research institutes and has been central to China's modern scientific development. Its 2015 budget was 54 billion yuan (US $\$ 8.4$ billion), a $9 \%$ increase from 2014 . we have also adopted more nuanced and individual-focused assessment criteria that are based on a researcher's relative performance compared to his or her peers," says Ren.

\section{DISCIPLINARY STRENGTHS}

China's booming scientific output is concentrated around specific subject areas, a trend that has continued since 2012. Chemistry and physical sciences clearly dominate the country's total publishing output in the Nature Index (see 'Chemistry champs'). The WFC figure for chemistry in 2014 was 3,783, accounting for $61 \%$ of the country's total WFC, while physical sciences made up 30\% of China's publishing output in the index. By comparison, distribution of the WFC in other subject areas are represented more proportionally in other top contributing countries, such as the United States, Germany and the United Kingdom.

The Chinese Academy of Sciences (CAS) is the top institutional producer in chemistry WFC, both in China and around the globe (see 'China's superstar'). The Institute of Chemistry (ICCAS) is the top contributing CAS institute by WFC. Its research strengths lie in molecular and nanosciences, organic and polymeric materials, chemical biology, as well as energy and green chemistry.

These cutting-edge areas of chemistry tend to have an applied aspect and are essential for industrial innovation. For instance, an ICCAS researchers' study on the assembly mechanism of organic composite materials strongly contributed to the development of flexible 


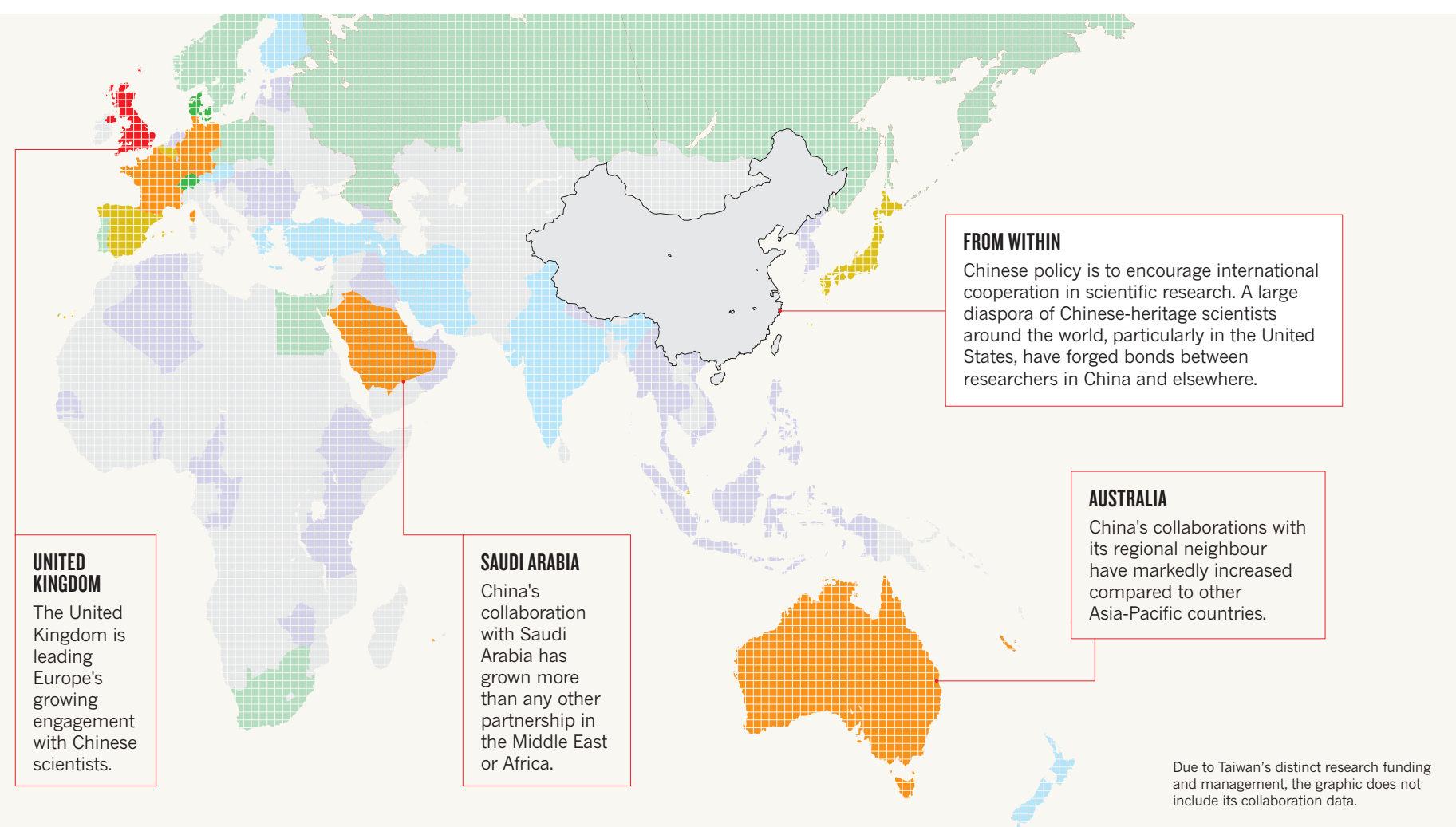

photonics and the realization of nanophotonic circuits for next-generation optical information processing.

The Chinese government has a crucial role directing the country's science and technology development. "The government's emphasis on the commercialization of high technology and the capacity of scientific research to drive industrial productivity possibly explains the strong focus on chemistry, particularly the subfields that are easily translated into commercial production," says Liu.

In line with the demands of the national development strategy, China is also making efforts to innovate in relatively newer fields in life sciences and envi-

"The nature of the scientific revolutionis long-term. China will lead more and more programmes." ronmental sciences such as energy, water resources, agriculture, environmental protection, and human health, which were identified as research priorities in 2006 in China's 15-year plan.

"Strong demand for new energy and the need to reduce pollutants emission in energy consumption will drive China's growth in environmental sciences," anticipates Liu, whose background is in this field.

Life sciences are also expected to make great advances in the near future. Between 2012 and 2014 , China's output in this area grew by $30 \%$. Fields such as genomics and protein sciences, stem cell and cloning technology, and gene therapy have already experienced significant progress. "[China is] set to become the global powerhouse of gene and protein research, leading this exciting field in life sciences and making grand discoveries with profound impacts," He explains.

\section{INCREASED INTERNATIONAL COLLABORATION}

Collaboration is an increasingly significant aspect of modern science and China's collaboration scores in the index reflect this trend. The recent Nature Index 2015 Collaborations supplement revealed that China's international partnerships are soaring, with its collaboration score rising $31 \%$ from 2012 to 2014 . Collaboration score is the sum of the fractional counts

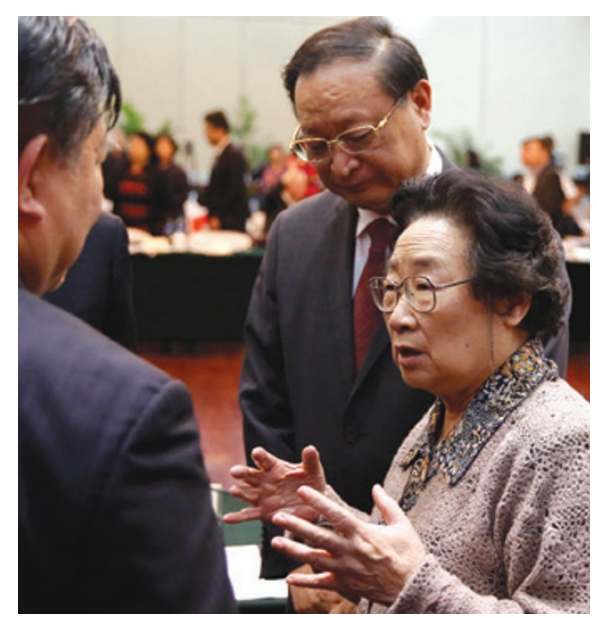

Winner of the Nobel Prize for Medicine, Tu Youyou.
(FC) for each of China's bilateral partnerships Almost half of China's international collaboration score in 2014 came from partnerships with the United States. Correspondingly, China has become the United States' largest collaborator, surpassing Germany in 2014. Other important international collaborators for China are other top contributing countries to the Nature Index, such as the United Kingdom and Japan (see 'Collaboration hotspots').

With the return of many Chinese scientists who have trained abroad, international collaborations are often based on personal ties. This has raised questions about China's role in these collaborations, some suggesting it is merely providing cheap labour working on ideas at the behest of former supervisors.

But in the past five years, Reiner says there has been a shift in these partnerships as Chinese scientists play a more significant role in the research and Chinese institutes contribute a greater proportion of the funding. In some international collaborations, for instance the Human Liver Proteome Project (HLPP) led by He, China is already setting scientific objectives and making important theoretical and technological innovations. "The nature of the scientific revolution is long-term," Reiner says. "As the output of scientific research from China is growing, I have no doubt that China will be leading more and more major international programmes, providing more important and, in some cases, critical contributions to international collaboration proportional to its input." 